\title{
Quantitative analysis of lipid deposits from Schnyder's corneal dystrophy
}

\author{
Masakazu Yamada, Hiroshi Mochizuki, Yuko Kamata, Yu Nakamura, Yukihiko Mashima
}

\begin{abstract}
Aim-To report the quantitation of the lipid composition of a corneal button from a Japanese woman in her 60s with clinically and histopathologically proved Schnyder's corneal dystrophy.

Methods-Total lipids extracted from the corneal button of the patient were analysed by the method of thin layer chromatography flame ionisation detection. Two different solvent systems were used for neutral lipid analysis and phospholipid analysis. Results were compared with three age matched corneal buttons obtained from cadaveric eyes.

Results-The lipids that accumulated in the cornea in Schnyder's dystrophy consisted mainly of unesterified cholesterol and phospholipids. The analysis of phospholipids showed sphingomyelin to be the predominant phospholipid in the patient's cornea.

Conclusion-Findings suggest that this disorder involves a disturbance of the metabolism of cholesterol and/or sphingomyelin metabolism that is limited to the cornea.

(Br f Ophthalmol 1998;82:444-447)
\end{abstract}

Schnyder's corneal dystrophy was first described by van Went and Wibaut ${ }^{1}$ and by Schnyder ${ }^{2}$ in the 1920 s. This autosomal dominant disease is characterised clinically by the presence of bilateral opacification in the central cornea that is sometimes associated with arcus lipoides, genu valgum, and hyperlipidaemia..$^{3-5}$

Histopathological examination of keratoplasty specimens from these patients has shown the presence of abnormal deposits of unesterified cholesterol, ${ }^{6-8}$ esterified cholesterol, ${ }^{9-11}$ and phospholipids ${ }^{11}$ in the basal epithelium, Bowman layer, stroma, ${ }^{6-12}$ and rarely, the endothelium. ${ }^{8}{ }^{12}$ Recently, the lipid fraction in Schnyder's dystrophy has been analysed quantitatively by McCarthy et al ${ }^{13}$ and Gaynor et al. ${ }^{14}$ Both groups reported that the lipids in the cornea in Schnyder's dystrophy consisted mainly of unesterified cholesterol and phospholipids. However, the detailed information of the composition of phospholipids has not been available so far. Recently, a large cohort of patients with Schnyder's dystrophy has been discovered in the United States. ${ }^{4}$ All patients described in that article had ancestors who had been born within a $100 \mathrm{~km}^{2}$ area on the southwest coast of Finland. Indeed, most reports of Schnyder's dystrophy are found in the European and American literature. The present paper con- cerns a Japanese woman with clinically and histopathologically proved Schnyder's corneal dystrophy. It is of interest to find out if a Japanese patient with Schnyder's dystrophy has the same biochemical features. We analysed the corneal button obtained from this patient to quantify the composition of neutral lipids and phospholipids by using thin layer chromatography (TLC) and a flame ionisation detection system.

\section{Case report}

A 61 year old Japanese woman was referred to the cornea clinic of Keio University Medical Center in July 1993 because of bilateral corneal opacities associated with a painless impairment of the vision for the past several years. Her best corrected visual acuity was right eye 20/100 and left eye 20/100. Slit lamp examination demonstrated a dense central stromal opacity with crystalline-like deposits and arcus lipoides in both corneas. The anterior chamber, iris, and lens were normal. The intraocular pressure and fundi were normal bilaterally. The patient's 32 year old son demonstrated similar corneal opacities. Her mother, who was dead, had had poor vision of undetermined aetiology.

Physical examination showed no xanthelasma or joint disorders. Results of urinalysis, blood cell counts, serum electrolytes, and serum proteins were normal. The plasma level of total cholesterol was marginally elevated (256 mg/dl; normal range, $135-250 \mathrm{mg} / \mathrm{dl}$ ) as were levels of unesterified cholesterol (70 $\mathrm{mg} / \mathrm{dl}$; normal range, 35-65 $\mathrm{mg} / \mathrm{dl}$ ) and phospholipids (294 mg/dl; normal range, 160 $290 \mathrm{mg} / \mathrm{dl}$ ). Triglycerides $(129 \mathrm{mg} / \mathrm{dl}$; normal range, $30-150 \mathrm{mg} / \mathrm{dl})$ and free fatty acids $(0.13$ $\mathrm{mEq} / 1$; normal range, $0.2-1.1 \mathrm{mEq} / \mathrm{l}$ ) were normal, as were plasma levels of lipoproteins and apolipoproteins.

The patient underwent penetrating keratoplasty in the left eye in May 1994. Histopathological examination revealed the panstromal deposition of lipid. A diagnosis of Schnyder's dystrophy was made based on clinical features, family history, and histopathological findings.

The opacification of the right cornea showed a gradual progression (Fig 1). The patient underwent penetrating keratoplasty in the right eye in February 1996. The corneal grafts have remained clear. To date, her best corrected visual acuity is right eye $20 / 30$ and left eye $20 / 40$.

\section{Methods}

The corneal button obtained from the patient's right eye was divided as follows-one half for quantitative lipid analysis by TLC, one quarter
Accepted for publication 11 November 1997 


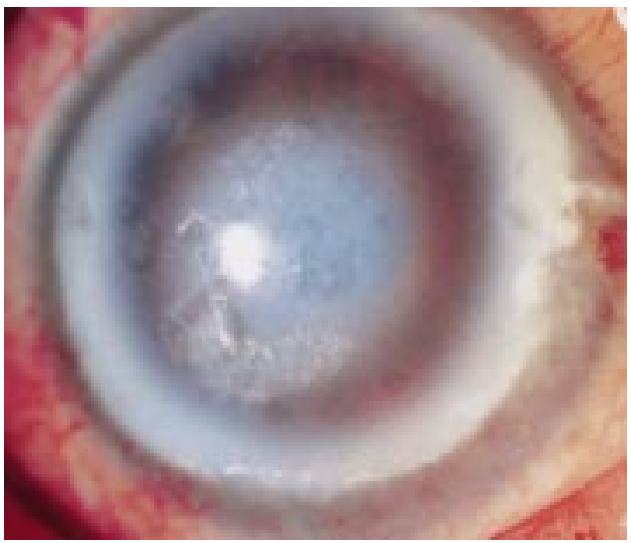

Figure 1 On slit lamp examination, right eye shows arcus lipoides and diffuse, central corneal opacity with subepithelial crystals.

for haematoxylin and eosin staining, and one quarter for oil red $\mathrm{O}$ staining. For controls in the lipid analysis, we used three equal sized, age matched, disease-free corneas from three cadavers.

Tissue for haematoxylin and eosin staining was fixed with $10 \%$ neutral buffered formalin, and was processed by standard methods. Frozen sections were prepared and stained with oil red $\mathrm{O}$ by the method of Adams. ${ }^{15}$

Corneal specimens from the patient and controls intended for lipid analysis were snap frozen in liquid nitrogen and stored at $-80^{\circ} \mathrm{C}$. Total lipids were extracted from the homogenised tissues according to the method of Folch et al. ${ }^{16}$ Samples were dried under nitrogen, redissolved in $20 \mu \mathrm{l}$ of chloroform:methanol mixture $(2: 1)$, and then 2-3 $\mu \mathrm{l}$ of samples applied to a chromarod coated with silica gel (Chromarod SIII, Yatoron, Tokyo). Lipids were separated by running the chromarod in a solvent system composed of n-hexane:ether:acetate $(90: 10: 0.025(\mathrm{v} / \mathrm{v} / \mathrm{v}))$ for total lipid analysis.

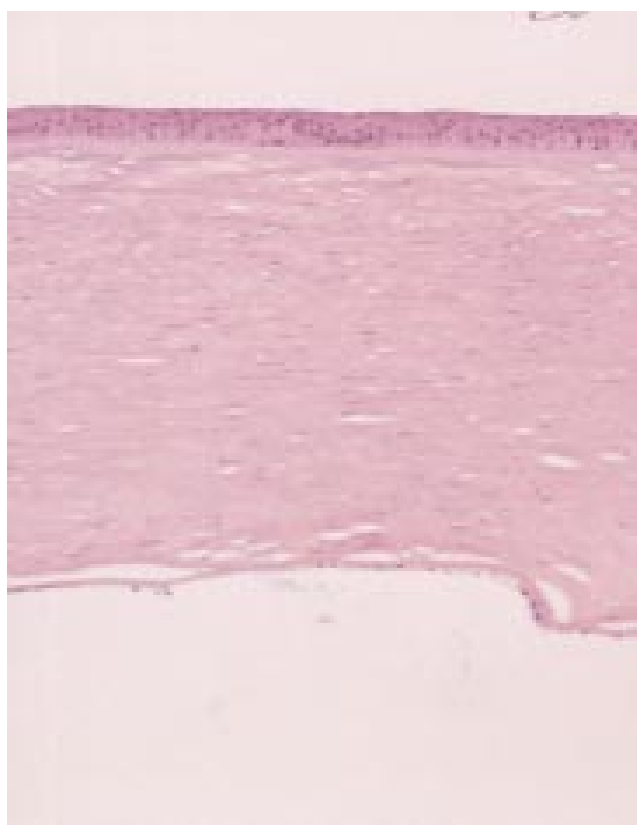

Figure 2 Photomicrograph of right corneal button. Loosened spaces representing dissolved lipids were present in the stroma (haematoxylin and eosin; original magnification, $\times 40$ ).

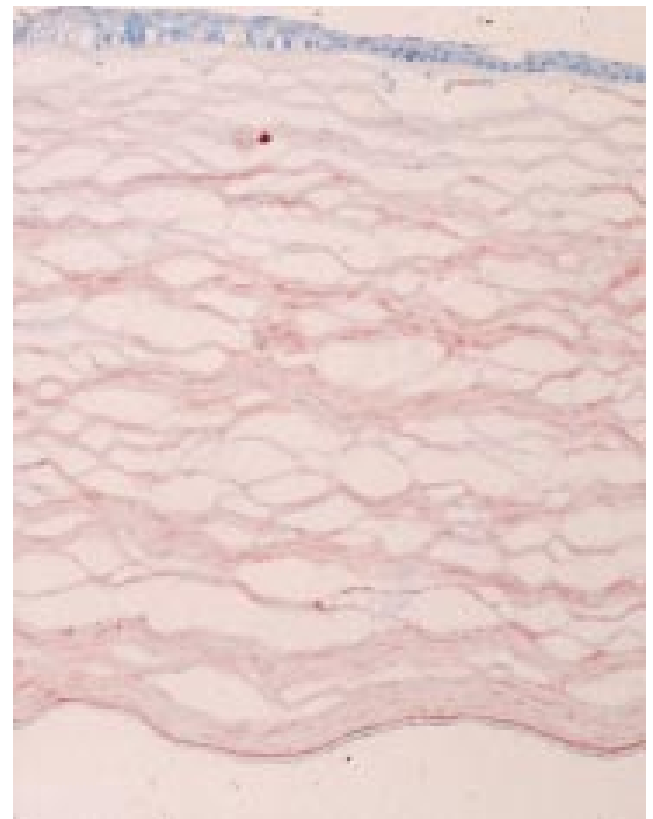

Figure 3 Photomicrograph of frozen section of the same corneal button stained with oil red $O$ shows panstromal reactivity (oil red $O$; original magnification, $\times 40$ ).

Another solvent system of chloroform:water:methanol $(60: 4: 35(\mathrm{v} / \mathrm{v} / \mathrm{v} /))$ was used for phospholipid analysis. The chromarod was dried at $110^{\circ} \mathrm{C}$ for 5 minutes. A flame ionisation detection iatroscan system (TH-10, Yatoron, Tokyo), was used for quantitation. This system consists of a hydrogen flame jet and an ion collector. While the sample was burnt, the ions were collected by the collector electrode. ${ }^{17}$ Flow rates of $2000 \mathrm{ml} / \mathrm{min}$ for air, and $160 \mathrm{ml} / \mathrm{min}$ for hydrogen were selected. A chromarod was scanned by the flame ionisation detector with a scan speed of $5.1 \mathrm{~mm} / \mathrm{s}$.

\section{Results}

The corneal epithelium and Bowman's layer appeared normal on histopathological examination. Loosened spaces representing dissolved lipids were present throughout the stroma. Signs of neovascularisation or inflammation were absent (Fig 2). Oil red $\mathrm{O}$ stain revealed diffuse positive staining of the entire stroma, although the staining of Bowman's layer was not apparent (Fig 3).

Table 1 and Figure 4 show the results of total lipid analysis of the corneas from the patient and controls. The most striking finding was an increase in the level of unesterified cholesterol $(\times 47)$ in the patient's cornea. Since the level of esterified cholesterol in the patient's cornea was higher than in controls, but to a lesser extent $(\times 4)$, there was a decrease in the ratio of esterified cholesterol/total cholesterol ratio. Only $14 \%$ of the cholesterol from the patient's cornea was esterified in contrast with $60-71 \%$ found in controls. Another unusual finding was the marked increase in phospholipid level $(x 12)$ in the patient's cornea. Quantitative phospholipid analysis revealed that the phospholipids in the patient's cornea consisted mainly of sphingomyelin ( $x \quad 33)$ and phosphatidylserine/phosphatidylinositol $(\times 18)$ 
Table 1 Quantitative distribution of neutral lipids in the cornea

\begin{tabular}{llllll}
\hline & Patient & Control 1 & Control 2 & Control 3 & Mean (range) in controls \\
\hline Age (years) & $65^{\star}$ & 60 & 69 & 62 & \\
Sex & $\mathrm{F}$ & $\mathrm{M}$ & $\mathrm{F}$ & $\mathrm{F}$ & \\
& (values are & $\mathrm{mg} / \mathrm{g}$ wet weight) & & \\
Esterified cholesterol & 1.61 & 0.39 & 0.45 & 0.36 & $0.40(0.36-0.45)$ \\
Triglycerides & $\mathrm{ND}$ & $\mathrm{ND}$ & $\mathrm{ND}$ & $\mathrm{ND}$ & $\mathrm{ND}$ \\
Free fatty acids & $\mathrm{ND}$ & 0.14 & 0.28 & 0.30 & $0.24(0.14-0.30)$ \\
Unesterified cholesterol & 9.95 & 0.22 & 0.18 & 0.24 & $0.21(0.18-0.24)$ \\
Monoglycerides + diglycerides & 1.15 & 1.88 & 1.46 & 1.63 & $1.66(1.46-1.88)$ \\
Phospholipids & 11.68 & 1.55 & 0.72 & 0.63 & $0.97(0.63-1.55)$ \\
\hline
\end{tabular}

*Age at the time of surgery.

$\mathrm{ND}=$ not detected.

compared with corneas of controls (Table 2 and Fig 5).

\section{Discussion}

Schnyder's corneal dystrophy is a rare hereditary autosomal dominant disease that is characterised by the abnormal deposition of lipid in the cornea. ${ }^{18}$ Our patient's clinical history and physical findings were consistent with a diagnosis of Schnyder's dystrophy. Both corneas exhibited a dense central stromal opacity with crystalline-like deposits and arcus lipoides. No neovascularisation or inflammation was seen on slit lamp or histological examination. Although the patient's plasma levels of cholesterol and phospholipid were marginally elevated, her levels of lipoproteins and apolipoproteins were normal. Similar corneal opacities were identified in the patient's 32 year old son, although an autosomal dominant mode could not be confirmed from the available family history.

The possibility of primary or secondary lipid degeneration was excluded in this case based on the clinical characteristics, histological findings, and family history. ${ }^{19}{ }^{20}$ The differential diagnosis should also consider dyslipoproteinaemias such as familial lecithin cholesterol acyltransferase (LCAT) deficiency, fish eye disease, and Tangier disease. ${ }^{18}{ }^{21}$ In our patient, the crystalline deposition was present in the corneal stroma, the high density lipoprotein component was not affected, and no systemic abnormalities were demonstrated. All these disorders, except for Schnyder's dystrophy, are inherited in an autosomal recessive mode. These findings led to the diagnosis of Schnyder's corneal dystrophy.

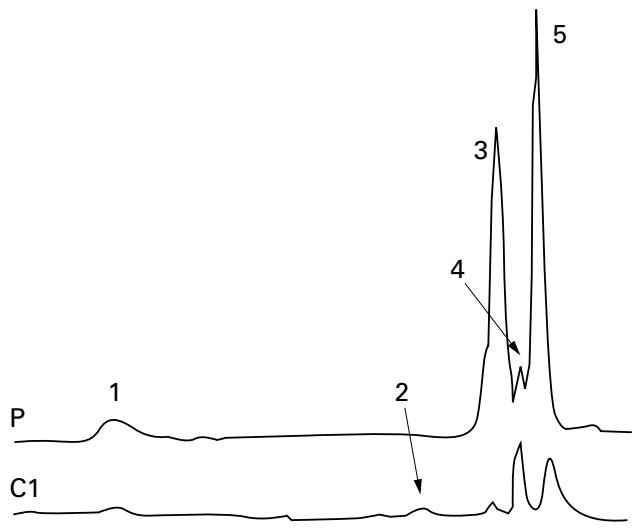

Figure 4 Chromatograms of neutral lipid analysis. (P) patient; (C1) control 1.1 = esterified cholesterol; 2 = free fatty acids; $3=$ unesterified cholesterol; $4=$ monoglycerides + diglycerides; and $5=$ phospholipids.
The lipid in Schnyder's dystrophy has been shown by various histological methods to contain unesterified cholesterol, esterified cholesterol, and phospholipids. ${ }^{6-11}$ Quantitative analyses of lipid deposition in the cornea have been reported; we identified two reports that included biochemical investigation of the lipid fraction in Schnyder's dystrophy. ${ }^{13}{ }^{14}$ Although the technique and method used in the present study differed from those of McCarthy et al ${ }^{13}$ and Gaynor et al, ${ }^{14}$ our results for the patient's cornea were consistent with those reports. Those authors described marked elevations in phospholipids, unesterified cholesterol, and, to a lesser extent, esterified cholesterol in Schnyder's cornea, as was found in our case $(\times 12$, $\times 47$, and $\times 4$, respectively). The results of biochemical analysis confirmed that unesterified cholesterol and phospholipids predominate in Schnyder's dystrophy. In addition, analysis of phospholipids in our case showed sphingomyelin to be the main phospholipid in the patient's cornea. The level of sphingomyelin was 33 times greater than that in normal control cornea; in contrast, the level of phosphatidylcholine, which predominated in the controls, was not elevated in the patient when compared with normal controls. An elevation of sphingomyelin has not previously been reported in Schnyder's dystrophy. This elevation is of interest because an increase in unesterified cholesterol and sphingomyelin concentrations has been reported in a cornea of a patient with primary lipid keratopathy. ${ }^{19}$ Although these two disorders differ clinically, certain similarities at the morphological and ultrastructural level have been pointed out by several authors. ${ }^{12}{ }^{20}$ Additionally, a patient with

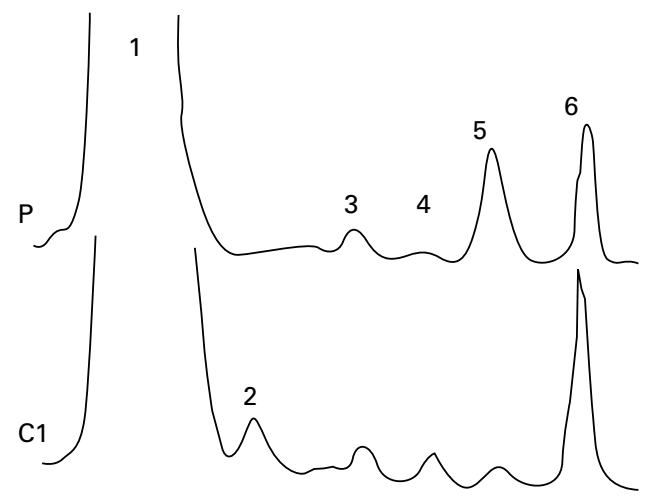

Figure 5 Chromatograms of phospholipids analysis. (P) patient; (C1) control 1.1 = neutral lipids; 2 = phosphatidylethanolamine; $3=$ phosphatidylserine + phosphatidylinositol; $4=$ phosphatidylcholine; 5 = sphingomyelin; and $6=$ origin. 
Table 2 Quantitative distribution of phospholipids in the cornea

\begin{tabular}{|c|c|c|c|c|c|}
\hline & Patient & Control 1 & Control 2 & Control 3 & Mean (range) in controls \\
\hline & \multicolumn{5}{|c|}{ (values are $\mathrm{mg} / \mathrm{g}$ wet weight) } \\
\hline Phosphatidylethanolamine & ND & 0.12 & ND & ND & $0.04(\mathrm{ND}-0.12)$ \\
\hline Phosphatidylserine + phosphatidylinositol & 2.31 & 0.11 & 0.07 & 0.20 & $0.13(0.07-0.20)$ \\
\hline Phosphatidylcholine & 0.46 & 0.08 & 0.13 & 0.67 & $0.30(0.08-0.67)$ \\
\hline Sphingomyelin & 4.63 & 0.06 & 0.09 & 0.28 & $0.14(0.06-0.28)$ \\
\hline Lysophosphatidylcholine & ND & ND & $\mathrm{ND}$ & ND & ND \\
\hline
\end{tabular}

$\mathrm{ND}=$ not detected.

Schnyder's dystrophy whose father has primary lipid degeneration has been reported. ${ }^{22}$ The similarity in the lipid content of the corneas in these two disorders supports the notion that they may be related.

The lipid components that accumulate in the cornea of patients with Schnyder's dystrophy resemble those in two other disorders with a systemic defect in lipid metabolism-LCAT deficiency and Niemann-Pick group of diseases. The accumulation of phospholipids and unesterified cholesterol in the liver, spleen, renal glomeruli, and the cornea has been found in LCAT deficiency. ${ }^{23}$ Increases in sphingomyelin and unesterified cholesterol in the spleen, lymph nodes, and bone marrow are prominent in patients with one of the Niemann-Pick diseases. ${ }^{24}$ Although Niemann-Pick diseases involve a disturbance of sphingomyelin metabolism in general, in type C Niemann-Pick disease, a primary disturbance in cholesterol esterification results in the secondary accumulation of sphingomyelin in the tissues. ${ }^{25} \mathrm{Al}-$ though it still cannot be determined whether the accumulation of sphingomyelin is primary, these facts lead us to consider that a decrease in the esterification of cholesterol in the cornea may be the underlying cause of Schnyder's dystrophy. The activities and expressions of enzymes of lipid metabolism should be measured in the cornea of patients with Schnyder's dystrophy to test this hypothesis. Genetic studies will also allow the determination of the pathogenesis of Schnyder's dystrophy, because the gene for Schnyder's corneal dystrophy is reported to map to human chromosome 1q34.1-p36, and several candidate genes are localised to this lesion. ${ }^{26}$

We have shown that the lipids that mainly accumulated in the cornea of a Japanese patient with Schnyder's dystrophy were unesterified cholesterol and phospholipids, especially sphingomyelin. Our results are consistent with the those of McCarthy et $a l^{13}$ and Gaynor et al. ${ }^{14}$ Although the pathogenesis of this disorder has not yet been determined, the pattern of lipid deposition in Schnyder's dystrophy resembles that reported in primary lipid degeneration, ${ }^{19}$ LCAT deficiency, ${ }^{23}$ and the Niemann-Pick group of diseases. ${ }^{24}$ Overall observations support the view that this disorder is a disturbance of the metabolism of cholesterol and/or sphingomyelin metabolism that is limited to the cornea. Further studies are required for a better understanding of this condition.
1 van Went JM, Wibaut F. Een zyeldzame erfelijke hoornvliesaandoening. Ned Tijdschr Geneeskd 1924;68 (1st half, B):2996-7.

2 Schnyder WF. Mitteilung über einen neuen Typus von familiärer Hornhauterkrankung. Schweiz Med Wochenschr 1929;59:559-71.

3 Bron AJ, Williams HP, Carruthers ME. Hereditary crystalline stromal dystrophy of Schnyder. I Clinical features of a family with hyperlipoproteinaemia. $\mathrm{Br} f$ Ophthalmol 1972;56:383-99.

4 Weiss JS. Schnyder's dystrophy of the cornea: a Swede-Finn connection. Cornea 1992;11:93-101.

5 Weiss JS. Schnyder crystalline dystrophy sine crystals: recommendation for a revision of nomenclature. Ophthalmology 1996;103:465-73.

6 Rodrigues MM, Kruth HS, Krachmer JH, et al. Unesterified cholesterol in Schnyder's corneal crystalline dystrophy. Am f Ophthalmol 1987;104:157-63.

7 Rodrigues MM, Kruth HS, Krachmer JH, et al. Cholesterol localization in ultrathin frozen sections in Schnyder's corneal crystalline dystrophy. Am F Ophthalmol 1990;110: 513-17.

8 Weiss JS, Rodrigues MM, Kruth HS, et al. Panstromal Schnyder's corneal dystrophy: ultrastructural and histochemical studies. Ophthalmology 1992;99:1072-81.

9 Delleman JW, Winkelman JE. Degeneratio corneae cristallineae hereditario: a chemical, genetical and histological study. Ophthalmologica 1968;155:409-26.

10 Garner A, Tripathi RC. Hereditary crystalline stromal dystrophy of Schnyder. II Histopathology and ultrastructure. Br F Ophthalmol 1972;56:400-8.

11 Weller RO, Rodger FC. Crystalline stromal dystrophy: histochemistry and ultrastructure of the cornea. $\mathrm{Br} \mathcal{F} O \mathrm{ph}$ thalmol 1980;64:46-52.

12 Freddo TF, Polack FM, Leibowitz HM. Ultrastructural changes in the posterior layers of the cornea in Schnyder's crystalline dystrophy. Cornea 1989;8:170-7.

13 McCarthy M, Innis S, Dubord P, et al. Panstromal Schnyder corneal dystrophy: a clinical pathologic report with quantitative analysis of corneal lipid composition. Ophthalmology 1994;101:895-901.

14 Gaynor PM, Zhang W-Y, Weiss JS, et al. Accumulation of HDL apolipoproteins abnormal cholesterol accumulation in Schnyder's corneal dystrophy. Arterioacler Thromb Vasc Biol 1996;16:992-9.

15 Adams CWM. The perchloric acid-naphthoquinone method for the histochemical localisation of cholesterol. Nature 1961;192:331-2.

16 Folch J, Lees M, Sloane-Stanley GH. A simple method for the isolation and purification of total lipids from animal tissues. F Biol Chem 1957;226:497-509.

17 Shantha NC. Thin-layer chromatography-flame ionization detection iatroscan system. F Chromatogr 1992;624:21-35.

18 Barchiesi BJ, Eckel RH, Ellis PP. The cornea and disorders of lipid metabolism. Surv Ophthalmol 1991;36:1-22.

19 Silva-Araújo A, Tavares MA, Lemos MM, et al. Primary lipid keratopathy: a morphological and biochemical assessment. Br f Ophthalmol 1993;77:248-50.

20 Savino DF, Fine BS, Alldredge OC Jr. Primary lipidic degeneration of the cornea. Cornea 1986;5:191-8.

21 Bron AJ. Corneal changes in the dislipoproteinaemias. Cornea 1989;8:135-40.

22 DiFerdinando R. Degeneratio cristallinea corneae hereditaria e forma affine. G Ital Oftalmol 1954;7:476-84.

23 Winder AF, Garner A, Sheraidah GA, et al. Familial lecithin:cholesterol acyltransferase deficiency: biochemislecithin:cholesterol acyltransferase deficiency:

24 Spence MW, Callahan JW. Sphingomyelin-cholesterol lipoidosis: the Niemann-Pick group of diseases. In: Scriver CR, Beaudet AL, Sly WS, Valle D, eds. The metabolic basis of inherited diseases. New York: MacGraw-Hill, 1989;11: 1665-76.

25 Pentchev PG, Comly ME, Kruth HS, et al. A defect in cholesterol esterification in Niemann-Pick disease (type C) patients. Proc Natl Acad Sci USA 1985;82:8247-51.

26 Sherman AM, Hudson TJ, Andresen JM, et al. The gene for Schnyder's crystalline corneal dystrophy maps to human chromosome 1p34.1-p36. Hum Mol Genet 1995;5:166772 . 